\title{
Safety and long-term efficacy of thoracoscopic Epicardial ablation in patients with paroxysmal atrial fibrillation: a retrospective study
}

John Johnkoski', Bryan Miles², Anna Sudbury², Mohammed Osman³, Muhammad Bilal Munir, Sudarshan Balla ${ }^{3}$ and Mina M. Benjamin ${ }^{3^{*}}$ (D)

\begin{abstract}
Background: The aim of this study is to report the long-term efficacy and safety of thoracoscopic epicardial left atrial ablation (TELA) in patients with paroxysmal atrial fibrillation (AF).

Methods: This was a retrospective review of medical records. We included all patients diagnosed with paroxysmal AF who underwent TELA at our institution between 04/2011 and 06/2017. TELA included pulmonary vein isolation, LA dome lesions and LA appendage exclusion. All $(n=55)$ patients received an implantable loop recorder (ILR), 30 days post-operatively. Antiarrhythmic and anticoagulation therapy were discontinued at 90 and 180 days postoperatively, respectively, if patients were free of AF recurrence. Failure was defined as $\geq$ two minutes of continuous AF, or atrial tachycardia.
\end{abstract}

Results: Fifty-five patients (78\% males, mean age $=61.6$ years) qualified for the study. The average duration in AF was $3.64+/-3.4$ years, mean CHA2DS2-VASc Score was $2.0+/-1.6$. The procedure was attempted in 57 patients and completed successfully in 55 (96.5\%). Two patients experienced a minor pulmonary vein bleed that was managed conservatively. Post procedure, one patient experienced pulmonary edema, another experienced a pneumothorax requiring a chest tube and another experienced acute respiratory distress syndrome resulting in longer hospitalization. Otherwise, there were no major procedural complications. Success rates were $89.1 \%$ ( $n=49$ / 55), $85.5 \%(n=47 / 55)$ and $76.9 \%(n=40 / 52)$ at 6,12 and 24 months, respectively. In the multivariate coxproportional hazard model, survival at the mean of covariates was 86 and $74 \%$ at 12 and 24 months, respectively.

Conclusion: In this single center experience, TELA was a safe and efficacious procedure for patients with paroxysmal AF.

Keywords: Atrial fibrillation, Arrhythmia, Thoracoscopic, Epicardial ablation, Anticoagulation, Pulmonary vein isolation, Implantable loop recorder

\footnotetext{
* Correspondence: mina.mehanni@hsc.wvu.edu

${ }^{3}$ Department of Internal Medicine (Division of Cardiovascular Medicine), West

Virginia University Hospitals, 1 Medical Center Dr, Morgantown, WV 26506,

USA

Full list of author information is available at the end of the article
}

(c) The Author(s). 2019 Open Access This article is distributed under the terms of the Creative Commons Attribution 4.0 International License (http://creativecommons.org/licenses/by/4.0/), which permits unrestricted use, distribution, and reproduction in any medium, provided you give appropriate credit to the original author(s) and the source, provide a link to the Creative Commons license, and indicate if changes were made. The Creative Commons Public Domain Dedication waiver (http://creativecommons.org/publicdomain/zero/1.0/) applies to the data made available in this article, unless otherwise stated. 


\section{Introduction}

Atrial fibrillation (AF) is the most common cardiac arrhythmia with several adverse consequences related to a reduction in cardiac output, and to ischemic cerebrovascular accidents or peripheral embolization due to atrial and atrial appendage thrombus formation [1]. Though AF is an independent risk factor of mortality, a causal relationship has not been established [2]. An attempt to maintain sinus rhythm is made in patients based on the presence or absence of symptoms and evidence that myocardial function is being compromised [3]. The most commonly performed invasive procedure used to maintain sinus rhythm is catheter ablation. The efficacy of catheter ablation may vary considerably, depending on the strategy and technology used and the stage of the electroanatomic disease [4]. In 2006, Wolf et al. [5] described a video-assisted thoracoscopic surgical ablation consisting of pulmonary vein isolation (PVI) from the epicardial side with a bipolar radiofrequency clamp, ablation of ganglia over the left atrial (LA) surface, and excision of the LA appendage. This procedure is performed with video-assisted thoracoscopic access to the epicardial space through small, either right-sided or bilateral thoracic incisions and primarily focuses on PVI. The pulmonary veins are electrically isolated with a bipolar radiofrequency ablation clamp or suction assisted unidirectional device. Additional ablation of ganglia or the left atrium can also be performed epicardially. As a stand-alone procedure, thoracoscopic epicardial left atrial ablation (TELA) is limited to PVI, either as a box or islands around each side. An endocardial approach is necessary to connect any lesion to either the mitral or tricuspid valves. Initial efficacy of TELA has been reported to be $>90 \%$ in selected populations $[6,7]$. Similar to traditional catheter ablation, there is no evidence that survival is improved with TELA $[8,9]$. The need for long-term anticoagulation after surgical ablation of AF remains unclear. TELA may reduce stroke risk and therefore the need for long-term anticoagulation. HRS/ EHRA/ECAS/APHRS/SOLAECE expert consensus statement on catheter and surgical ablation of atrial fibrillation recommends stand-alone surgical ablation as a reasonable option for persistent and long-standing patients who have failed one or more attempts at catheter ablation who prefer a surgical approach after review of safety and efficacy of options. For paroxysmal AF, it may also be considered after one or more catheter attempts [10]. The Society of Thoracic Surgeons 2017 Clinical Practice Guidelines for the Surgical Treatment of Atrial Fibrillation recommends stand-alone surgical ablation for symptomatic AF without structural heart disease in patients who have failed a class I or III antiarrhythmic medication or catheter-based therapy [11]. The aim of this retrospective study was to assess the long-term efficacy and safety of TELA as a stand-alone procedure in patients with paroxysmal atrial fibrillation.

\section{Methods}

This study was a retrospective review of medical records. We included all patients diagnosed with paroxysmal AF who underwent TELA at our institution between 04/ 2011 and 06/2017. The patients did not tolerate or have failed antiarrhythmic drugs. At that time interval, there was no dedicated electrophysiology service at the hospital. The surgeon (JJ), explained the TELA procedure to patients. Patients were also informed that catheter-based PVI was the gold standard for ablation procedures, and they were offered a referral to a center where catheterbased ablation can be performed. Patients who denied a referral and opted to undergo TELA were included in this study.

Exclusion criteria for the procedure were previous lung lobectomy, or pericardial surgery and a body mass index above $35 \mathrm{~kg} / \mathrm{m}^{2}$. Patients' anticoagulation drugs were held prior to the procedure and resumed the night following the procedure. The procedure included PVI, ganglia mapping and ablation, left atrial dome lesions, superior vena cava lesion, and left atrial appendage exclusion. Under general anesthesia, three $10 \mathrm{~mm}$ ports sites were created. The right side was performed first. The pericardium was opened and retracted posteriorly. Using the AtriCure ${ }^{\circledR}$ Transpolar Pen, the autonomic ganglia were mapped and ablated, and then the AtriCure ${ }^{\circ}$ Lumitip Dissector was used to encircle the pulmonary venous hilum and to guide the AtriCure ${ }^{\bullet}$ Synergy Bipolar RF Clamp around the veins. Three separate lines of ablations were performed with each being repeated twice. Bidirectional block was then confirmed with the pen at each location. An opening was created between the superior vena cava and venous hilum. Working through the transverse sinus, the right-sided portion of the LA dome lesion was created with the AtriCure Coolrail linear pen. This lesion was repeated twice. Working through the oblique sinus, the right-sided portion of the LA floor lesion was created, and this lesion was repeated twice as well. A superior vena cava lesion is created well above the area of the sinus node with a single application of the radiofrequency clamp. On the left side, the autonomic ganglia and veins were treated identically, and the dome and floor lesions were completed. Bidirectional block was confirmed for the both veins and the box. Autonomic ganglia were localized in the anterior and posterior fat pads, by their response to high-frequency stimulation. Successful ganglion ablation was defined by abolition of the heart rate response ( $\geq 50 \%$ increase in $\mathrm{R}-\mathrm{R}$ interval) to high-frequency stimulation at the same regions that had elicited clear responses before ablation. Coolrail $^{\circledR}$ device was then used 
to perform the LA appendage connecting lesion, which consisted of a line on the posterior surface of the LA appendage and several stamping lesions over the base of the LA appendage in the coumadin ridge area. Finally, the LA appendage was excluded with AtriClip ${ }^{\circ}$ with the aid of transesophageal imaging to confirm a residual of less than $1 \mathrm{~cm}$ at the base. Bidirectional block was then confirmed on the LA appendage. The pericardium was then reapproximated, and a chest tube placed. Chest tubes were typically pulled later the day of the procedure. Patients were discharged from the hospital, the day following the procedure, unless a complication occurred. All patients received an implantable loop recorder (ILR), 30 days post-operatively. Antiarrhythmic and anticoagulation therapy were discontinued at 90 and 180 days postoperatively, respectively, if patients were free of AF recurrence. Failure was defined as $2 \mathrm{~min}$ or more, of continuous AF or flutter on any ILR download. Procedural complications were defined as major when prolonging or causing a hospital admission within 30 days.

\section{Statistical analysis}

Continuous data are reported as mean \pm standard deviation, and categoric data are reported as number of subjects and ratios. The differences between the groups were compared using the independent-samples Student's t-test. Chi-square statistics were used to compare categorical variables between groups. Cox-proportional hazard survival analysis was also conducted. Variables were entered in the model if their univariate test $p$-value was $\leq 0.2$. Statistical analysis was conducted using MedCalc Statistical Software version 16.4.3 (MedCalc Software, Ostend, Belgium; https://www. medcalc.org; 2016).

\section{Results}

Fifty-five patients underwent TELA during the study period. Seven (12.5\%) had previous catheter ablation procedures before the index procedure. Baseline patient demographics, comorbidities, and echocardiographic characteristics are included in Table 1 . The mean age of patients was $61.6+/-10.7$ years. Forty-four $(80 \%)$ were

Table 1 Baseline demographics, clinical characteristics, and echocardiographic values

\begin{tabular}{|c|c|c|c|c|c|c|}
\hline & All $(n=55)$ & No recurrence $(n=36)$ & Recurrence $(n=19)$ & P-value & $\mathrm{HR}$ & $95 \% \mathrm{Cl}$ \\
\hline \multicolumn{7}{|l|}{ Demographics } \\
\hline Age & $61.6+/-10.7$ & $60.0+/-11.6$ & $64.9+/ 11.6$ & 0.104 & 1.02 & $0.99-1.07$ \\
\hline Males & $44(80.0 \%)$ & $26(72.2 \%)$ & $18(94.7 \%)$ & 0.722 & 0.82 & $0.27-2.48$ \\
\hline Duration in AF (years) & $3.6+/-3.4$ & $3.5+/-3.5$ & $3.4+/-3.0$ & 0.513 & 1.35 & $0.84-1.53$ \\
\hline CHA2DS2-VASC Score & $2.0+/-1.6$ & $1.9+/-1.5$ & $2.2+/-1.7$ & 0.89 & 0.98 & $0.73-1.3$ \\
\hline \multicolumn{7}{|l|}{ Comorbidities } \\
\hline Hypertension & $32(58.2 \%)$ & $17(47.2 \%)$ & 15 (78.9\%) & 0.187 & 1.69 & $0.64-4.46$ \\
\hline Hyperlipidemia & $26(47.3 \%)$ & $13(36.1 \%)$ & $13(68.4 \%)$ & 0.686 & 1.2 & $0.49-2.97$ \\
\hline Obstructive sleep apnea & $5(9.1 \%)$ & $2(5.6 \%)$ & $3(15.8 \%)$ & 0.035 & 3.34 & $1.09-10.28$ \\
\hline Coronary artery disease & $7(12.7 \%)$ & $3(8.3 \%)$ & $4(21.1 \%)$ & 0.745 & 0.81 & $0.24-2.81$ \\
\hline Cerebrovascular disease & 0 & 0 & 0 & & & \\
\hline Diabetes mellitus & $6(10.9 \%)$ & $4(11.1 \%)$ & $2(10.6 \%)$ & 0.981 & 1.02 & $0.23-4.42$ \\
\hline \multicolumn{7}{|l|}{ Echocardiographic values } \\
\hline Ejection Fraction (\%) & $61.8+/-5.6$ & $61.0+/-6.2$ & $62.2+/-4.3$ & 0.506 & 1.03 & $0.94-1.19$ \\
\hline Mitral regurgitation & & & & & 4.01 & $0.93-20.57$ \\
\hline Mild & $35(63.6 \%)$ & $17(47.2 \%)$ & 17 (89.5\%) & 0.056 & & \\
\hline Moderate or severe & 0 & 0 & 0 & & & \\
\hline Tricuspid regurgitation & & & & & 1.81 & $0.51-6.46$ \\
\hline Mild & $30(54.5 \%)$ & $18(50.0 \%)$ & $12(63.3 \%)$ & 0.99 & & \\
\hline Moderate & $1(1.8 \%)$ & 0 & $1(5.3 \%)$ & 0.57 & & \\
\hline RA dilation & & & & & 1.52 & $0.48-4.83$ \\
\hline Mild & $10(18.2 \%)$ & $5(9.1 \%)$ & $5(26.3 \%)$ & 0.484 & & \\
\hline Moderate & $2(3.6 \%)$ & 0 & $2(10.5 \%)$ & 0.180 & & \\
\hline LA diameter $(\mathrm{cm})$ & $4.0+/-0.6$ & $3.9+/-0.6$ & $4.0+/-0.5$ & 0.296 & 1.74 & $0.79-5.01$ \\
\hline LA volume index $(\mathrm{cm} / \mathrm{m} 2)$ & $29.3+/-8.0$ & $27.4+/-5.8$ & $31.1+/-9.4$ & 0.374 & 1.56 & $0.42-5.93$ \\
\hline
\end{tabular}


men. The mean duration in AF was $3.6+/-3.4$ years and the mean CHA2DS2-VASc Score was $2.0+/-1.6$. None of the patients had severe valvular disease. The mean left atrial volume index was $29.3+/-8 \mathrm{~mL} / \mathrm{m}^{2}$. The mean follow-up period was $36.8+/-21$ months. Figure 1 shows a graphical representation of the percentage of patients receiving oral anticoagulation and/or antiarrhythmic medications at different time points. Success rates were $89.1 \%(n=49 / 55), 85.5 \% \quad(n=47 / 55)$ and $76.9 \%(n=40 / 52)$ at 6,12 and 24 months, respectively. In the multivariate cox-proportional hazard model, survival at the mean of covariates was 88,86 and $74 \%$ at 6 , 12 and 24 months, respectively (Fig. 2). None of the patients in our study experienced cerebrovascular accidents during follow up.

The procedure was attempted in 57 patients and completed successfully in $55(96.5 \%)$ patients. One patient experienced tension pneumothorax and the other experienced a major bleed during TELA and those two patients were converted to a full sternotomy for AF ablation. Two patients experienced a minor pulmonary vein bleed that was managed conservatively. Post procedure, one patient experienced pulmonary edema, another experienced a pneumothorax requiring a chest tube and another experienced acute respiratory distress syndrome resulting in longer hospitalization. Otherwise, there were no procedural complications, including phrenic nerve injury, esophageal fistula, major bleeding, hemothorax, cardiovascular or cerebrovascular events. At the end of the follow up period, none of the patients experienced any cerebrovascular accidents.

\section{Discussion}

This study investigated the long-term efficacy and safety of TELA as a stand-alone procedure in paroxysmal AF patients, using ILR for follow up. The major finding of our study is that the efficacy of TELA was similar to previously published studies using catheter-based PVI.

$\mathrm{n}$ a metanalysis of 19 studies, the pooled 12 -month success rate for the 11 studies reporting outcomes for paroxysmal AF patients was $66.6 \%$ (95\% CI 58.2 to $74.2 \%$ ). Single-procedure freedom from atrial arrhythmia at longterm follow-up was $54.1 \%$ (95\% CI 44.4 to $63.4 \%$ ) in paroxysmal AF patients. The multiple-procedure long-term success in paroxysmal AF was $79.0 \%$ in 8 studies $(95 \%$ CI 67.6 to $87.1 \%$ ) [9].

The efficacy results of our study are similar to previous TELA studies. There is a limited number of publications which reported the long-term efficacy of TELA as a stand-alone procedure for restoration of sinus rhythm in AF patients, likely because it was first described -only- a little more than a decade ago. Edgerton et al. reported the results of a prospective, nonrandomized study of 52 consecutive patients with symptomatic paroxysmal AF undergoing TELA [6]. Unlike our study where all patients received an ILR, monitoring was obtained by either a 24-h Holter monitor, 2- to 3-week event monitoring, or interrogation of an implanted pacemaker. Freedom from AF/flutter/tachycardia was 86.3 and $80.8 \%$ at 6 months and 1 year, respectively. The FAST trial randomly assigned 124 patients with antiarrhythmic drug-refractory AF with LA dilatation and hypertension (33\%) or failed prior catheter ablation (67\%) to either

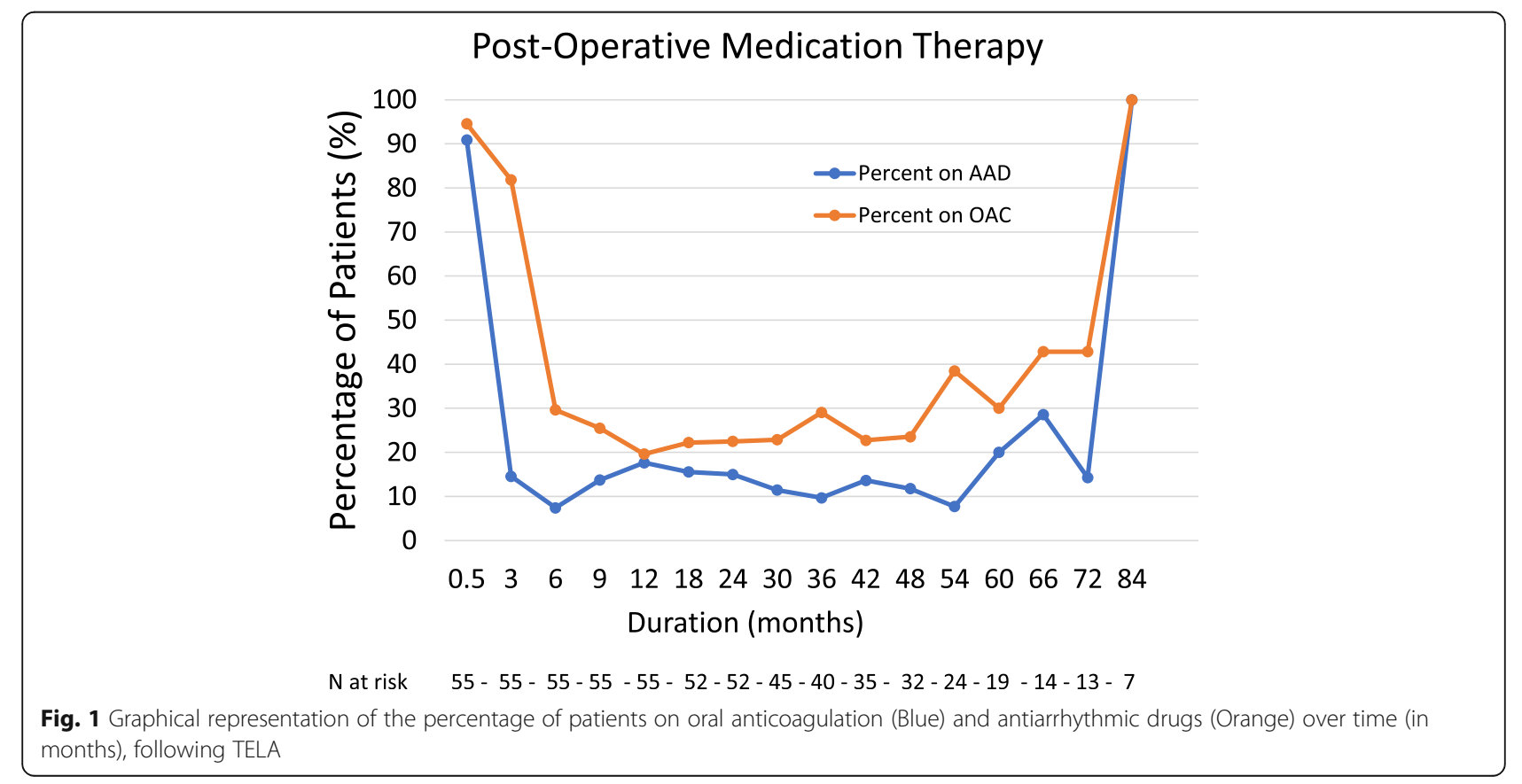


Survival at mean of covariates

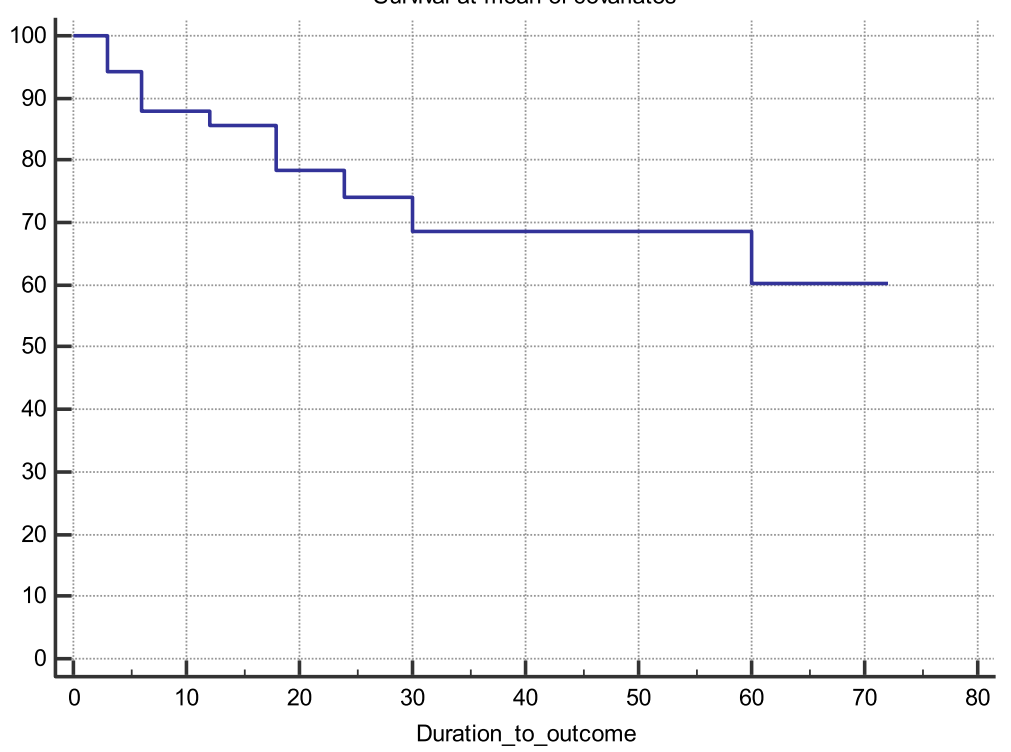

Fig. 2 Cox-proportional hazard model of the freedom from atrial arrhythmias over time (in months) following TELA, at the mean of the following covariates: age, hypertension, obstructive sleep apnea, left atrial volume and mitral regurgitation

minimally invasive surgical ablation or catheter ablation. At 12 months, the primary end point of freedom from LA arrhythmia of greater than $30 \mathrm{~s}$ without antiarrhythmic drugs was significantly higher in the surgical ablation group (65.6 versus 36.5\%). However, there were significantly more periprocedural complications such as pneumothorax, major bleeding, and the need for pacemaker in the surgical ablation group (35.4 versus $15.9 \%$ ) [8]. Rosati et al., reported the results of biatrial ablation in 49 consecutive patients with AF who underwent right-sided monolateral thoracoscopic ablation. Twentyfour hours ECG Holter monitoring was used as the primary means of defining AF recurrences. At 13 months, 43 patients $(87.7 \%)$ of patients were in sinus rhythm; 35 (71.4\%) were free from antiarrhythmic drugs and 37 (75.5\%) from oral anticoagulation [12].

None of the patients in our study experienced cerebrovascular accidents during follow up. With an average CHA2DS2VASc score of 2, the estimated stroke risk for our population would be $2.2 \%$ per year and $2.9 \%$ combined risk of stroke, transient ischemic attacks or systemic embolization $[13,14]$. The novelty of this study comes from exclusively studying paroxysmal AF patients with a longer follow up period than the previous reports. Also, all patients received an ILR, which can identify AF recurrences when they are very infrequent [15].

\section{Limitations}

Limitations of this study include all the inherent limitations of a retrospective study, and the absence of a control group. The Heart Rhythm Society defines failure following an ablation procedure as more than $30 \mathrm{~s}$ of $\mathrm{AF}$ and this study used a cutoff of 2 min which is the lowest reported by an ILR. Also, there were no postprocedural studies conducted to assess the restoration of atrial mechanical function, in this cohort.

\section{Conclusions}

In this retrospective single center experience, TELA was a safe and efficacious procedure for patients with paroxysmal AF. Long-term outcomes are similar to the gold standard of catheter-based PVI. Results need to be validated in a randomized clinical trial fashion to compare the safety, efficacy and quality of life metrics between patients with atrial fibrillation undergoing thoracoscopic epicardial versus catheter-based ablation procedures.

\section{Abbreviations}

AF: Atrial fibrillation; ILR: Implantable loop recorder; PVI: Pulmonary vein isolation; TELA: Thoracoscopic epicardial left atrial ablation

\section{Acknowledgments \\ Not applicable}

\section{Authors' contributions}

$J J$ and $\mathrm{MB}$ authored the manuscript. BM, AS and MO conducted the chart review and statistical analysis. MO, MM and SB independently reviewed and edited the manuscript. All authors read and approved the final manuscript.

Funding

This study received no funding.

\section{Availability of data and materials}

All data generated or analysed during this study are included in this published article. 


\section{Ethics approval and consent to participate}

Aspirus Wausau hospital institutional review board (IRB) approval date: 1/18/ 2019 Reference number: 19.01.524X

\section{Consent for publication}

Not applicable

\section{Competing interests}

The authors declare that they have no competing interests.

\section{Author details}

'Department of Cardiothoracic Surgery, Aspirus Wausau Hospital, 2400 Pine Ridge Blvd, Wausau, WI 54401, USA. ${ }^{2}$ School of Medicine, Medical College of Wisconsin, 8701 W Watertown Plank Rd, Wauwatosa, WI 53226, USA.

${ }^{3}$ Department of Internal Medicine (Division of Cardiovascular Medicine), West Virginia University Hospitals, 1 Medical Center Dr, Morgantown, WV 26506, USA.

Received: 6 August 2019 Accepted: 28 October 2019

Published online: 06 November 2019

\section{References}

1. Atrial fibrillation: current understandings and research imperatives. The National Heart, Lung, and Blood Institute working group on atrial fibrillation. J Am Coll Cardiol. 1993;22(7):1830-4.

2. Leong DP, Eikelboom JW, Healey JS, Connolly SJ. Atrial fibrillation is associated with increased mortality: causation or association? Eur Heart J. 2013;34(14):1027-30.

3. January CT, Wann LS, Alpert JS, Calkins H, Cigarroa JE, Cleveland JC Jr, et al. 2014 AHA/ACC/HRS guideline for the management of patients with atrial fibrillation: a report of the American College of Cardiology/American Heart Association task force on practice guidelines and the Heart Rhythm Society. J Am Coll Cardiol. 2014;64(21):e1-76.

4. Lubitz SA, Fischer A, Fuster V. Catheter ablation for atrial fibrillation. BMJ. 2008;336(7648):819-26.

5. Wolf RK, Schneeberger EW, Osterday R, Miller D, Merrill W, Flege JB Jr, et al. Video-assisted bilateral pulmonary vein isolation and left atrial appendage exclusion for atrial fibrillation. J Thorac Cardiovasc Surg. 2005;130(3):797-802.

6. Beyer $\mathrm{E}$, Lee $\mathrm{R}$, Lam BK. Point: minimally invasive bipolar radiofrequency ablation of lone atrial fibrillation: early multicenter results. J Thorac Cardiovasc Surg. 2009;137(3):521-6.

7. Edgerton JR, Brinkman WT, Weaver T, Prince SL, Culica D, Herbert MA, et al. Pulmonary vein isolation and autonomic denervation for the management of paroxysmal atrial fibrillation by a minimally invasive surgical approach. J Thorac Cardiovasc Surg. 2010;140(4):823-8.

8. Boersma LV, Castella M, van Boven W, Berruezo A, Yilmaz A, Nadal M, et al. Atrial fibrillation catheter ablation versus surgical ablation treatment (FAST): a 2-center randomized clinical trial. Circulation. 2012;125(1):23-30.

9. Ganesan AN, Shipp NJ, Brooks AG, Kuklik P, Lau DH, Lim HS, et al. Longterm outcomes of catheter ablation of atrial fibrillation: a systematic review and meta-analysis. J Am Heart Assoc. 2013;2(2):e004549.

10. Calkins H, Hindricks G, Cappato R, Kim YH, Saad EB, Aguinaga L, et al. 2017 HRS/EHRA/ECAS/APHRS/SOLAECE expert consensus statement on catheter and surgical ablation of atrial fibrillation. Heart Rhythm. 2017;14(10):e275-444.

11. Badhwar V, Rankin JS, Damiano RJ Jr, Gillinov AM, Bakaeen FG, Edgerton JR, et al. The Society of Thoracic Surgeons 2017 clinical practice guidelines for the surgical treatment of atrial fibrillation. Ann Thorac Surg. 2017;103(1):329-41.

12. Rosati F, Muneretto C, Merati E, Polvani G, Moltrasio M, Tondo C, et al. Epicardial, Biatrial ablation with integrated Uni-bipolar radiofrequency technology in stand-alone persistent atrial fibrillation. Innovations (Phila). 2018;13(2):114-9.

13. Lip GY, Nieuwlaat R, Pisters R, Lane DA, Crijns HJ. Refining clinical risk stratification for predicting stroke and thromboembolism in atrial fibrillation using a novel risk factor-based approach: the euro heart survey on atrial fibrillation. Chest. 2010;137(2):263-72.

14. Friberg $L$, Rosenqvist M, Lip GY. Evaluation of risk stratification schemes for ischaemic stroke and bleeding in 182678 patients with atrial fibrillation: the Swedish atrial fibrillation cohort study. Eur Heart J. 2012;33(12):1500-10.
15. Afzal MR, Gunda S, Waheed S, Sehar N, Maybrook RJ, Dawn B, et al. Role of outpatient cardiac rhythm monitoring in cryptogenic stroke: a systematic review and meta-analysis. Pacing Clin Electrophysiol. 2015;38(10):1236-45.

\section{Publisher's Note}

Springer Nature remains neutral with regard to jurisdictional claims in published maps and institutional affiliations.

\section{Ready to submit your research? Choose BMC and benefit from:}

- fast, convenient online submission

- thorough peer review by experienced researchers in your field

- rapid publication on acceptance

- support for research data, including large and complex data types

- gold Open Access which fosters wider collaboration and increased citations

- maximum visibility for your research: over $100 \mathrm{M}$ website views per year

At $\mathrm{BMC}$, research is always in progress.

Learn more biomedcentral.com/submissions 